\title{
Implicit motor learning promotes neural efficiency during laparoscopy
}

\author{
Frank F. Zhu $\cdot$ Jamie M. Poolton • Mark R. Wilson • \\ Yong Hu $\cdot$ Jon P. Maxwell $\cdot$ Rich S. W. Masters
}

Received: 13 December 2010/ Accepted: 6 February 2011/Published online: 1 April 2011

(C) The Author(s) 2011. This article is published with open access at Springerlink.com

\begin{abstract}
Background An understanding of differences in expert and novice neural behavior can inform surgical skills training. Outside the surgical domain, electroencephalographic (EEG) coherence analyses have shown that during motor performance, experts display less coactivation between the verbal-analytic and motor planning regions than their less skilled counterparts. Reduced involvement of verbal-analytic processes suggests greater neural efficiency. The authors tested the utility of an implicit motor learning intervention specifically devised to promote neural
\end{abstract}

F. F. Zhu · J. M. Poolton $(\bowtie) \cdot$ J. P. Maxwell

R. S. W. Masters

Institute of Human Performance, The University of Hong Kong,

Pokfulam, Hong Kong, People's Republic of China

e-mail: jamiep@hku.hk

F. F. Zhu

e-mail: ffzhu@hku.hk

R. S. W. Masters

e-mail: mastersr@hku.hk

\section{F. F. Zhu · J. M. Poolton}

Department of Surgery, The University of Hong Kong,

Pokfulam, Hong Kong, People's Republic of China

M. R. Wilson

College of Life and Environmental Sciences, The University

of Exeter, Exeter, UK

e-mail: mark.wilson@ex.ac.uk

Y. Hu

Department of Orthopaedics and Traumatology, The University of Hong Kong, Pokfulam, Hong Kong, People's Republic of China efficiency by reducing verbal-analytic involvement in laparoscopic performance.

Methods In this study, 18 novices practiced a movement pattern on a laparoscopic trainer with either conscious awareness of the movement pattern (explicit motor learning) or suppressed awareness of the movement pattern (implicit motor learning). In a retention test, movement accuracy was compared between the conditions, and coactivation (EEG coherence) was assessed between the motor planning $(\mathrm{Fz})$ region and both the verbal-analytic (T3) and the visuospatial (T4) cortical regions (T3-Fz and T4-Fz, respectively).

Results Movement accuracy in the conditions was not different in a retention test $(P=0.231)$. Findings showed that the EEG coherence scores for the T3-Fz regions were lower for the implicit learners than for the explicit learners $(P=0.027)$, but no differences were apparent for the T4-Fz regions $(P=0.882)$.

Conclusions Implicit motor learning reduced EEG coactivation between verbal-analytic and motor planning regions, suggesting that verbal-analytic processes were less involved in laparoscopic performance. The findings imply that training techniques that discourage nonessential coactivation during motor performance may provide surgeons with more neural resources with which to manage other aspects of surgery.

Keywords EEG coherence - Implicit motor learning · Surgery skills $\cdot$ Verbal-analytic processing

Recently, study investigating the neural substrate that underpins how trainees and experts produce surgical skills at a cortical level has begun to provide a foundation upon 
which to base the development and refinement of surgical training strategies [1-5]. Trainee surgeons, for example, have been shown to display significant activation of the prefrontal cortex early in learning when their skills are error-prone but not later in learning when their skills have automated [4, 6]. However, a greater understanding of how cortical regions interact in response to surgical training is needed [7].

Outside the surgical domain, electroencephalographic (EEG) measurement has shaped much of our current understanding concerning the neurocognitive aspects of skilled motor performance [8-10]. Experts display "neural efficiency," in which cortical activity is refined and nonessential interaction between the motor planning regions and other regions of the brain is attenuated [11-16]. Neuroplasticity of the cortical architecture is thought to reflect lowered demands on attention and reduced cognitive interference in motor planning and execution [8].

A specific neural measure with potential to discriminate between expert and novice motor performance is EEG cortical coherence between the verbal-analytic (T3) and motor planning $(\mathrm{Fz})$ regions $[17,18]$. High coherence suggests extensive coactivation (communication) between the two regions, whereas low coherence implies trivial coactivation (regional independence). Elite marksmen, for example, exhibit lower T3-Fz alpha band coherence than their subelite counterparts [17]. Interestingly, coherence between the visuospatial processing (T4) and motor planning $(\mathrm{Fz})$ regions $(\mathrm{T} 4-\mathrm{Fz})$ does not differ, suggesting that neural efficiency is not represented by a uniform decrease in cerebral activity, but rather by an appropriate "fit" of neural resources to specific task demands and a consequent reduction in irrelevant processing [8]. By withdrawing verbal-analytic engagement from motor performance, experts reduce neuromotor "noise" and limit potential interference from nonessential processes.

The need for verbal-analytic involvement in motor performance at any stage of learning has been questioned [19-21]. Verbal-analytic processes can interfere with motor performance and have been implicated in skill breakdown under psychological stress [19, 20, 22, 23] and physiologic fatigue [24, 25]. Additionally, inexperienced performers who depend on verbal-analytic processes tend to be disrupted by multitasking conditions [26-28].

Implicit motor learning techniques are designed to circumvent verbal-analytic interference during training. They result in low conscious awareness of what is learned and subsequently limited verbal-analytic involvement in motor performance $[19,29]$, as reflected by low T3-Fz alpha band co-activation [30]. Implicit motor learning has potential, therefore, to promote neural efficiency in surgical training. We examined this possibility in a laparoscopic surgery task.

\section{Materials and methods}

For this study, 18 volunteers with no prior laparoscopy experience were recruited from the University of Hong Kong student community. All the participants were righthanded, with normal or corrected-to-normal vision.

A continuous tracking task [31-33] was modified to be highly relevant to laparoscopy training. In continuous tracking paradigms, a learner tracks a target moving in a sinusoidal waveform across a monitor by manipulating a handheld device in the horizontal plane. The waveform contains a prescribed movement pattern that is repeated in every trial but embedded between two random movement patterns that differ in every trial (Fig. 1). With training, participants become very skilled at tracking the repeated segment of the pattern. They can be informed that the pattern repeats and asked to search consciously for it (explicit motor learning), or they can be completely unaware that the pattern repeats (implicit motor learning).

To modify the tracking task for laparoscopy, the handheld device was replaced by laparoscopic graspers inserted through a trocar in a simulated skin pad. The graspers were used bimanually to maneuver a tracker across an Intuos 3 tablet (Wacom, JP, Saitama, Japan). The position of the tracker on the tablet (horizontal plane) corresponded to the position of a cursor on a 17-in. liquid crystal display (LCD) monitor adjusted to the height of the operator.

To simulate scaling of sensorimotor mappings in laparoscopy due to magnification of the operating area by the endoscope, the movement of the cursor was scaled to match the movement of the tracker $(\times 8)$. The study participants were required to track as accurately as possible a red target dot that moved in a sinusoidal waveform across the computer screen. The task was designed in response to recent criticism of the overemphasis on completion time measures in surgical training curricula [34].

The participants were assigned to an explicit motor learning condition $(n=9)$ or an implicit motor learning condition $(n=9) .{ }^{1}$ All the participants were informed that they would see a red dot on the screen for $36 \mathrm{~s}$ and that the dot would display a waveform pattern of movement.

The participants in the explicit motor learning condition were told that the middle 12-s segment of the pattern would be the same for every trial and that they would need to learn the pattern to improve the accuracy of their movements. Additionally, they were shown a pictorial representation of the repeating segment at the beginning of training and after every three practice trials (Fig. 1, middle

\footnotetext{
$\overline{1}$ The novelty of the research question made it difficult to determine appropriate power for the sample; however, the sample sizes of the two learning conditions were in accord with contemporary EEG and implicit motor learning research [12, 17, 19, 32].
} 
Fig. 1 A visual representation of waveform patterns from two exemplar trials. The middle $12-\mathrm{s}$ segment was repeated in every trial and embedded between two 12 -s segments that differed in every trial

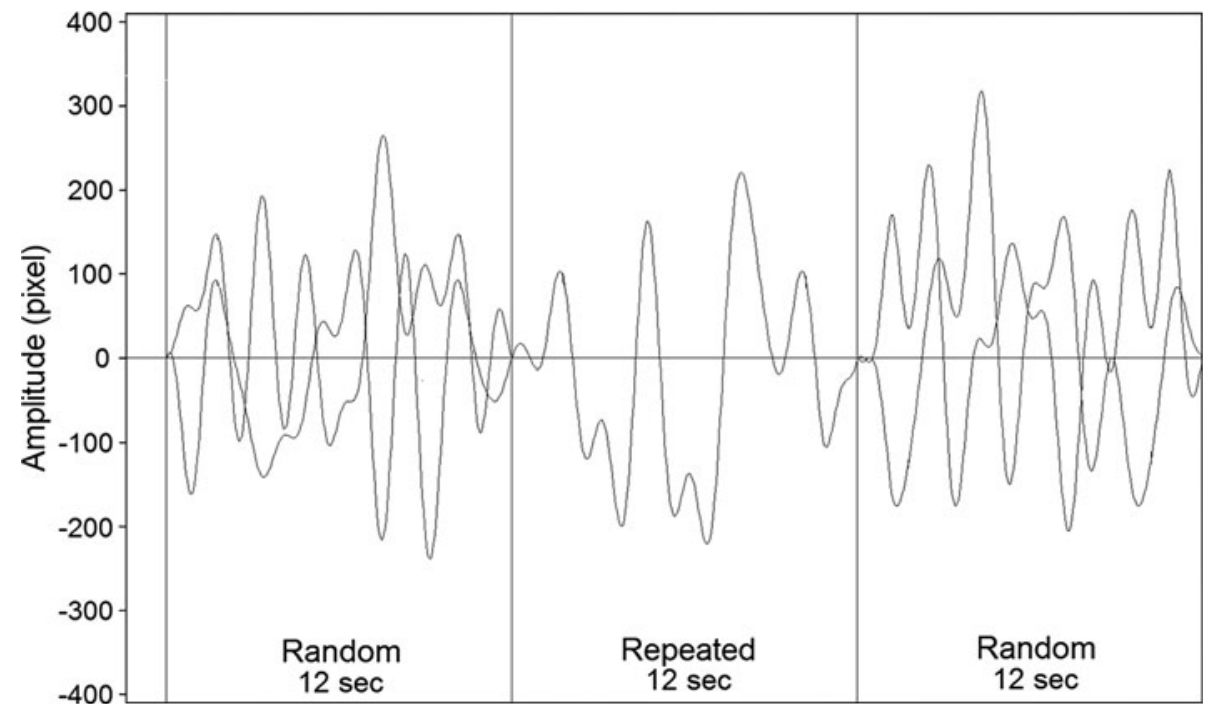

segment). This information was designed explicitly to encourage verbal-analytic involvement in performance of the laparoscopy task. The participants in the implicit motor learning condition were not informed that the middle segment of the waveform pattern repeated, nor did they see a pictorial representation of the repeated segment. ${ }^{2}$

Training consisted of eight blocks of three trials $(n=24$ trials). A 1-min rest interval was provided between blocks. At $5 \mathrm{~min}$ after the final training block, all the participants completed a retention test ( $n=3$ trials). Retention tests typically are used to assess "true" learning once participants have recovered from fatigue or boredom that accumulates during training [35].

A custom Java program (Sun Microsystems, Santa Clara, CA, USA) generated the movement patterns and recorded both the target and cursor locations at a sampling rate of $32 \mathrm{~Hz}$. Tracking accuracy, indexed by root mean square error (RMSE), was calculated for the repeated pattern of movement in each trial. The mean RMSE was computed for each block of learning and the retention test.

Electroencephalographic activity was recorded throughout the retention test and in a 1-min standing baseline that immediately preceded the test. Activity was recorded from seven scalp locations (Fp1, Fp2, T3, T4, Fz, Cz, Pz) referenced to linked earlobes using a stretchable electrode cap (ElectroCap Inc., Eaton, OH, USA) in accordance with the standard international 10-20 system [36]. The ground electrode was located at the mid forehead. The EEG was recorded and stored (bandpass filter, $1-45 \mathrm{~Hz}$; notch filter, $50 \mathrm{~Hz}$; sample rate, $1,000 \mathrm{~Hz}$ ) using a NeuroTop EEG system (Symtop Instruments, Beijing, People's Republic of China). Before each measurement, an impedance test

\footnotetext{
${ }^{2}$ Manipulation checks at the end of the experiment showed that no participant in the implicit condition was aware of the repeating segment.
}

ensured a sufficient signal-to-noise ratio. The EEG data for the $12 \mathrm{~s}$ of the repeated movement pattern were extracted for processing and analysis.

Electroencephalographic artifacts caused by eye blinks were removed by independent component analysis (ICA [37]). An experienced EEG technician visually inspected the recordings and removed any other potential biologic artifacts (e.g., muscle activation or glosso-kinetic artifacts). Artifacts were distinguished from cortical activity according to the duration, morphology, and rate of firing. A Hamming window (1,024 sample and 50\% overlap) then was applied to the data in preparation for coherence analysis.

Neural efficiency in visuomotor tasks is characterized by reduced T3-Fz but not T4-Fz alpha band coherence [14, 17]. Therefore, T3-Fz and T4-Fz coherences were calculated in $0.49-\mathrm{Hz}$ frequency bins and averaged across the alpha frequency bandwidth $(8-12 \mathrm{~Hz})[14,17]$. Both coherence estimates were subjected to a Fisher's $z$ transformation

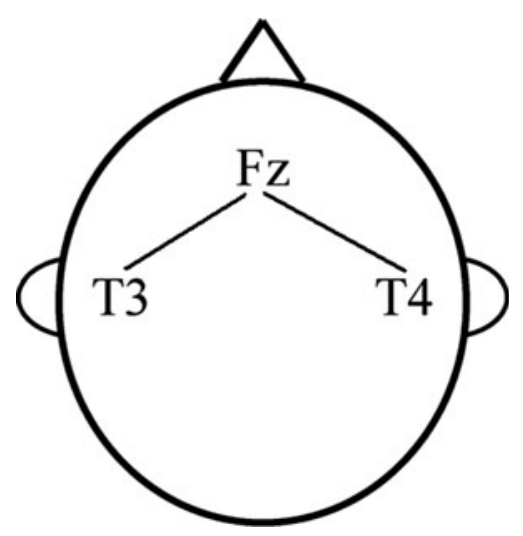

Fig. 2 The cortical locations of interest for the current study. Fz: frontal midline premotor region (motor planning). T3: left hemisphere temporal lobe (verbal-analytic processing). T4: right hemisphere temporal lobe (visuospatial processing) 
before analysis to ensure normal distribution. The processing and analysis steps described earlier were implemented with the EEGLAB toolbox [37] and custom scripts in MATLAB (MathWorks, Natick, MA, USA). Figure 2 provides a schematic of the cortical sites subjected to coherence analysis.

\section{Results}

Laparoscopic task performance

To determine whether the implicit and explicit training interventions resulted in improved movement accuracy (RMSE), a group $\times$ block $(2 \times 8)$ analysis of variance (ANOVA) with repeated measures on the latter factor was performed. A main effect of block was evident $(F=14.156$, $\left.\mathrm{df}=7.112 ; \quad P<0.001 ; \eta^{2}=0.469\right)$, with mean RMSE decreasing for both conditions during training. No group $\times$ block interaction was evident $(F=0.459 ; \mathrm{df}=7.112$; $\left.P=0.862 ; \eta^{2}=0.028\right)$, but there was a main effect of group $\left(F=5.180 ; \mathrm{df}=1.16 ; P=0.037 ; \eta^{2}=0.245\right)$.

The mean RMSE tended to be lower for the explicit motor learning condition than for the implicit motor learning condition during training. However, this difference was not present during the retention test $(t=1.245$; $\mathrm{df}=16 ; P=0.231$ ) (Fig. 3).

\section{EEG coherence}

To determine whether implicit and explicit training resulted in different levels of neural coactivation between the verbal-analytic (T3) and motor planning (Fz) regions (T3-Fz coherence) and between the visuospatial (T4) and motor planning (Fz) regions (T4-Fz coherence), separate one-way analyses of covariance (ANCOVA) were computed using

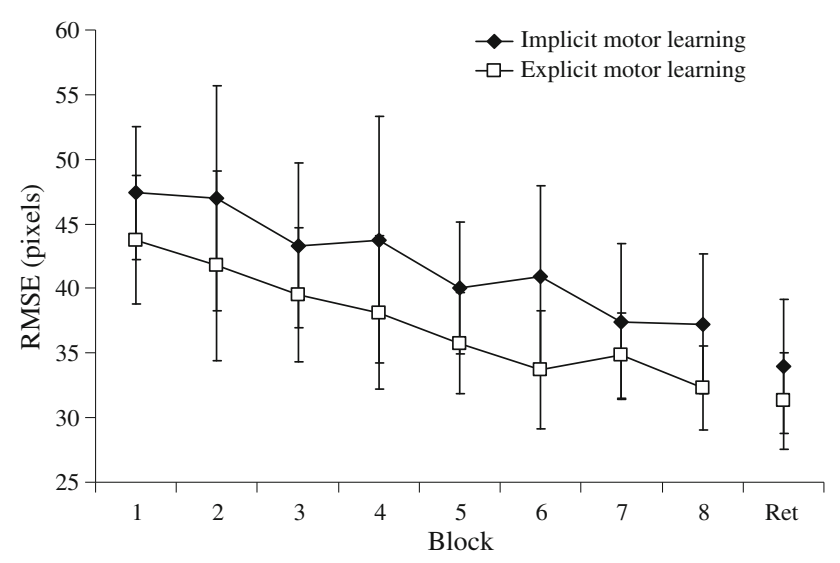

Fig. 3 Movement accuracy RMSE of the implicit and explicit motor learning groups throughout the training blocks (1-8) and in the retention test (Ret) (mean \pm standard error)

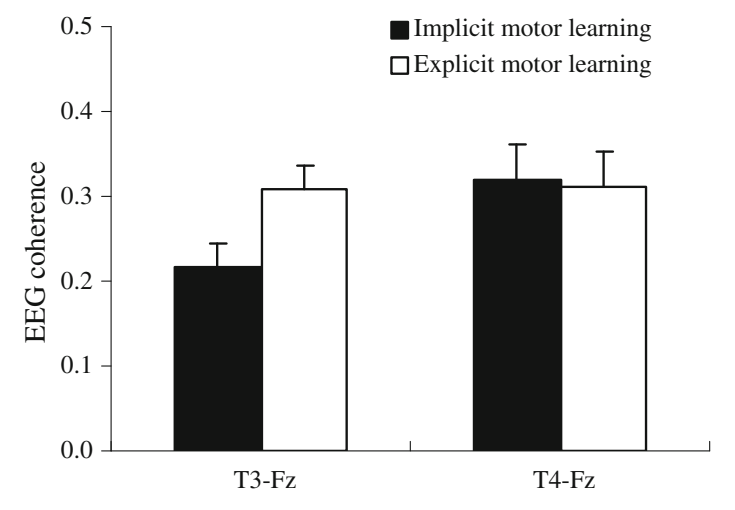

Fig. 4 Electroencephalographic alpha T3-Fz and T4-Fz coherence in the retention test (mean \pm standard error)

standing baseline coherence as the covariate. The analyses showed a significant difference in T3-Fz coherence scores during the retention test $(F=5.984 ; \mathrm{df}=1.15 ; P=0.027$; $\left.\eta^{2}=0.285\right)$ but no difference in T4-Fz coherence scores $\left(F=0.023 ; \mathrm{df}=1.15 ; P=0.882 ; \eta^{2}=0.002\right)$. As illustrated in Fig. 4, T3-Fz coherence was lower for the participants in the implicit condition than for the participants in the explicit condition, suggesting that verbal-analytic involvement in performance of the repeated movement pattern was reduced by implicit motor learning.

\section{Discussion}

This study aimed to further our understanding of how different motor learning paradigms have an impact on the neural architecture, underpinning laparoscopic performance. Specifically, we examined whether implicit motor learning promotes more efficient deployment of neural resources, as quantified by EEG coherence. We predicted that implicit motor learning would limit verbal-analytic involvement in performance of the laparoscopy task, thereby reducing nonessential alpha bandwidth coactivation of the left temporal region responsible for verbalcognitive processing (T3) and the frontal midline premotor region of the cortex involved in movement planning $(\mathrm{Fz})$ $[14,38]$.

Movement accuracy improved in both training conditions, although accuracy in the implicit motor learning condition was generally lower than in the explicit motor learning condition during training. This difference was not present in the retention test (Fig. 3), suggesting that with respect to movement accuracy at least, the training interventions were equally effective for the laparoscopy task. Informing participants that there was a repeating segment (explicit condition) appears to have benefited performance but not learning. This phenomenon is not uncommon in the motor learning literature, in which benefits of one form of 
practice over another are seen in training but not in retention tests (e.g., see guided learning vs trial-and-error learning [39]; blocked practice vs random practice [40]).

Regardless, our analysis of the neural activity underpinning performance suggests that the training interventions culminated in different levels of neural efficiency. Consistent with our predictions, EEG alpha bandwidth $\mathrm{T} 3-\mathrm{Fz}$ coherence was lower for the implicit motor learning condition than for the explicit motor learning condition during the retention test, implying that implicit motor learners used less verbal-analytic control to support motor performance than explicit motor learners. No differences were evident for EEG T4-Fz coherence, however, suggesting that visuospatial processing was essential for performance of the task and thus was little reduced by training. The same argument has been made for other visuomotor tasks [16-18].

Taken together, our data suggest that implicit motor learning allowed learners to achieve the same level of technical proficiency as explicit motor learning but with greater neural efficiency. Our findings are consistent with functional Magnetic Resonance Imaging (fMRI) studies showing that repetition of a motor task (practice) results in adaptations of neural activation that do not match accompanying improvements in the speed or accuracy of motor performance [41].

Proficiency levels for standardized laparoscopy tasks are extrapolated from the performance of highly experienced surgeons. Trainees generally reach proficiency levels on the standardized tasks within as few as 6-80 repetitions $[42,43]$ but fall short of the "true" expertise of the master surgeon. For example, contemporary research has identified multitasking as a key surgical stressor, demonstrating that the technical proficiency of inexperienced surgeons (let alone trainees [28]) is disrupted when verbal-analytic resources are demanded by concurrent tasks [44-46]. The main advantage of implicit motor learning, therefore, is not that novices will be quicker to attain movement proficiency, but rather that greater neural efficiency (i.e., more expert-like mapping of neural resources to task demands) allows them to deploy resources more easily to other nontechnical aspects of surgical performance. Indeed, preliminary research has shown that implicit motor learning interventions facilitate effective multitasking during the completion of a surgical knot-tying procedure [47].

The EEG technique clearly offers many benefits for researchers seeking to examine the neural substrate underpinning surgical performance and learning. It has excellent temporal resolution; it is relatively cheap and unobtrusive (compared with fMRI or positron emission topography); and its utility is supported by decades of research in other dynamic visuomotor task environments [8-10, 14]. However, research adopting a variety of methods and protocols (e.g., functional near-infrared spectroscopy [2]) is needed if we are to support surgical training fully with objective data based on changes in cortical activation. Nevertheless, our findings provide support for the efficacy of implicit motor learning in laparoscopy training. Reduced verbal-analytic involvement in movement seems likely to promote neural efficiency during performance, freeing up resources to deal with other nontechnical aspects of surgical performance when they arise.

Acknowledgments Dr. Jon Maxwell passed away on Sunday, 25 January 2009, during the preparation of this study. Jonny Max inspired us and challenged our thinking always. We were privileged to have the opportunity to work with him. This work was supported by a bilateral research grant from the Economic and Social Research Council, UK, and the Research Grants Council, Hong Kong (RES000-22-3016), awarded to the third and last authors. Dr Wilson's involvement was facilitated by a 6-month fellowship in Hong Kong funded by the Department of Business, Innovation and Skills, UK.

Disclosures Frank F. Zhu, Jamie M. Poolton, Mark R. Wilson, Yong Hu, Jon P. Maxwell, and Rich S. W. Masters have no conflicts of interest or financial ties to disclose.

Open Access This article is distributed under the terms of the Creative Commons Attribution Noncommercial License which permits any noncommercial use, distribution, and reproduction in any medium, provided the original author(s) and source are credited.

\section{References}

1. Wanzel KR, Anastakis DJ, McAndrews MP, Grobar ED, Sidhu RS, Taylor K, Mikulis DJ, Hamstra SJ (2007) Visual-spatial ability and fMRI cortical activation in surgery residents. Am J Surg 193:507-510

2. Leff DR, Leong JJH, Aggarwal R, Yang G-Z, Darzi A (2008) Could variations in technical skills acquisition in surgery be explained by differences in cortical plasticity? Ann Surg 247:540-543

3. Leff DR, Leong JJH, Yang G-Z, Darzi AW (2008) Visuospatial ability and fMRI cortical activation in surgery residents. Am J Surg 195:138

4. Ohuchida K, Kenmotsu H, Yamamoto A, Sawada K, Hayami T, Morooka K, Takasugi S, Konishi K, Leiri S, Tanoue K, Iwamoto Y, Tanaka M, Hashizume M (2009) The frontal cortex is activated during learning of endoscopic procedures. Surg Endosc 23:2296-2301

5. Sugden C, Aggarwal R (2010) Assessment and feedback in the skills laboratory and operating room. Surg Clin N Am 90: 519-533

6. Leff DR, Elwell CE, Orihuela-Espina F, Atallah L, Delpy DT, Darzi AW, Yang GZ (2008) Changes in prefrontal cortical behaviour depend upon familiarity on a bimanual co-ordination task: an fNIRS study. Neuroimage 39:805-813

7. Leff DR, James DRC, Orihuela-Espina F, Yang G-Z, Darzi AW (2010) The frontal cortex is activated during learning of endoscopic procedures (Ohuchida et al, Surg Endosc, January 2009). Surg Endosc 24:968-969

8. Hatfield BD, Haufler AJ, Hung TM, Spalding TW (2004) Electroencephalographic studies of skilled psychomotor performance. J Clin Neurophysiol 21:144-156 
9. Janelle CM, Hatfield B (2008) Visual attention and brain processes that underlie expert performance: implications for sport and military psychology. Mil Psychol 20:117-134

10. Yarrow K, Brown P, Krakauer JW (2009) Inside the brain of an elite athlete: the neural processes that support high achievement in sports. Nat Rev Neurosci 10:585-596

11. Milton J, Solodkin A, Hlustik P, Small SL (2007) The mind of expert motor performance is cool and focused. Neuroimage 35:804-813

12. Bablioni C, Del Percio C, Iacoboni M, Infarinato F, Lizio R, Marzano N, Crespi G, Dassu F, Pirritano M, Gallamini M, Eusebi F (2008) Golf putt outcomes are predicted by sensorimotor cerebral EEG rhythms. J Physiol 586:131-139

13. Baumeister J, Reinecke K, Liesen H, Weiss M (2008) Cortical activity of skilled performance in a complex sports related motor task. Eur J Appl Physiol 104:625-631

14. Hatfield B, Haufler A, Contreras-Vidal J (2009) Brain processes and neurofeedback for performance enhancement of precision motor behavior. Lect Notes Comput Sci 5638:810-817

15. Haufler AJ, Spalding TW, Santa Maria DL, Hatfield BD (2000) Neuro-cognitive activity during a self-paced visuospatial task: comparative EEG profiles in marksmen and novice shooters. Biol Psychol 53:131-160

16. Kerick SE, McDowell K, Hung TM, Santa Maria DL, Spalding TW, Hatfield BD (2001) The role of the left temporal region under the cognitive motor demands of shooting in skilled marksmen. Biol Psychol 58:263-277

17. Deeny SP, Hillman CH, Janelle CM, Hatfield BD (2003) Corticocortical communication and superior performance in skilled marksmen: an EEG coherence analysis. J Sport Exerc Psychol 25:188-204

18. Zhu FF, Maxwell JP, Hu Y, Zhang ZG, Lam WK, Poolton JM, Masters RSW (2010) EEG activity during the verbal-cognitive stage of motor skill acquisition. Biol Psychol 84:221-227

19. Masters RSW (1992) Knowledge, knerves, and know-how: the role of explicit versus implicit knowledge in the breakdown of a complex motor skill under pressure. Br J Psychol 83:343-358

20. Masters RSW, Maxwell JP (2008) The theory of reinvestment. Int Rev Sports Exerc Psychol 1:160-183

21. Masters RSW, Poolton JM, Abernethy B, Patil NG (2008) Implicit learning of movement skills for surgery. ANZ J Surg 78:1062-1064

22. Hardy L, Mullen R, Jones G (1996) Knowledge and conscious control of motor actions under stress. Br J Psychol 86:621-636

23. Masters RSW, Polman RCJ, Hammond NV (1993) Reinvestment: a dimension of personality implicated in skill breakdown under pressure. Pers Indiv Differ 14:655-666

24. Masters RSW, Poolton JM, Maxwell JP (2008) Stable implicit motor processes despite aerobic locomotor fatigue. Conscious Cogn 17:335-338

25. Poolton JM, Masters RSW, Maxwell JP (2007) Passing thoughts on the evolutionary stability of implicit motor behaviour: performance retention under physiological fatigue. Conscious Cogn $16: 456-468$

26. Maxwell JP, Masters RSW, Eves FF (2003) The role of working memory in motor learning and performance. Conscious Cogn $12: 376-402$

27. Maxwell JP, Masters RSW, Kerr E, Weedon E (2001) The implicit benefit of learning without errors. Q J Exp Psychol A 54:1049-1068

28. Poolton JM, Wilson MR, Malhotra N, Ngo K, Masters RSW (in press) A comparison of evaluation, time pressure, and multitasking as stressors of psychomotor operative performance. Surgery
29. Masters RSW, Maxwell JP (2004) Implicit motor learning, reinvestment, and movement disruption: what you don't know won't hurt you? In: Williams AM, Hodges NJ (eds) Skill acquisition in sports: research, theory and practice. Routledge, London, pp 207-228

30. Zhu FF, Poolton JM, Wilson MR, Maxwell JP, Masters RSW (2011) Neural co-activation as a yardstick of implicit motor learning and the propensity for conscious control of movement. Biol Psychol

31. Boyd LA, Winstein CJ (2006) Explicit information interferes with implicit motor learning of both continuous and discrete movement tasks after stroke. JNPT 30:46-57

32. Pew RW (1974) Levels of analysis in motor control. Brain Res 71:393-400

33. Wulf G, Schmidt RA (1997) Variability of practice and implicit motor learning. J Exp Psychol Learn 23:987-1006

34. Schout BMA, Hendrix AJM, Scheele F, Bemelmans BLH, Scherpbier AJJA (2010) Validation and implementation of surgical simulators: a critical review of present, past, and future. Surg Endosc 24:536-546

35. Schmidt RA, Lee TD (1999) Motor control and learning: a behavioral emphasis, 3rd edn. Human Kinetics, Champaign

36. Jasper HH (1958) The ten-twenty electrode system of the International Federation. Electroencephalogr Clin Neurol 17:37-46

37. Delorme A, Makeig S (2004) EEGLAB: an open source toolbox for analysis of single-trial EEG dynamics including independent component analysis. J Neurosci Methods 134:9-21

38. Kaufer DI, Lewis DA (1999) Frontal lobe anatomy and cortical connectivity. In: Miller B, Cummings J (eds) The human frontal lobes. Guilford Press, New York, pp 27-45

39. Prather DC (1971) Trial-and-error versus errorless learning: training, transfer, and stress. Am J Psychol 84:377-386

40. Magill RA, Hall KG (1990) A review of the contextual interference effect in motor skill acquisition. Hum Mov Sci 9:241-289

41. Landau SM, Schumacher EH, Garavan H, Druzgal TJ, D’Esposito M (2004) A functional MRI study of the influence of practice on component processes of working memory. Neuroimage 22:211-221

42. Aggarwal R, Crochet A, Dias A, Misra A, Ziprin P, Darzi A (1009) Development of a virtual reality training curriculum for laparoscopic cholecystectomy. Br J Surg 96:1086-1093

43. Scott DJ, Ritter EM, Tesfay ST, Pimentel EA, Nagji A, Fried GM (2008) Certification pass rate of $100 \%$ for fundamentals of laparoscopic surgery skills after proficiency-based training. Surg Endosc 22:1887-1893

44. Moorthy K, Munz Y, Dosis A, Bann S, Darzi A (2003) The effect of stress-inducing conditions on the performance of a laparoscopic task. Surg Endosc 17:1481-1484

45. Schuetz M, Gockel I, Beardi J, Hakman P, Dunschede F, Moenk S, Heinrichs W, Junginger TH (2008) Three different types of surgeon-specific stress reactions identified by laparoscopic simulation in a virtual scenario. Surg Endosc 22:1263-1267

46. Andreatta PB, Hillard M, Krain LP (2010) The impact of stress factors in simulation-based laparoscopic training. Surgery 147:631-639

47. Masters RSW, Lo CY, Maxwell JP, Patil NG (2008) Implicit motor learning in surgery: implications for multi-tasking. Surgery 143:140-145 